\title{
Aspectos simbólicos envolvidos em atividade grupal para pessoas que convivem com HIV ${ }^{1}$
}

\author{
Jennifer Bazilio² \\ Claudinei José Gomes Campos ${ }^{3}$
}

Trata-se de um trabalho qualitativo e descritivo, que se utilizou do método clínico e qualitativo. A amostra foi composta por nove pacientes que vivem com HIV. Utilizamos a técnica de entrevista com perguntas semiestruturadas, para coletar os dados. Estes foram analisados pelo método da análise de conteúdo. Nosso objetivo foi descrever as representações simbólicas emergentes durante a atividade em grupo, atribuídas a pacientes portadores de HIVIAIDS. Concluímos que o simbólico é muito forte e representativo na vida desta população. O mito que cerca o HIV pode ser rompido pelo conhecimento adquirido durante encontros em grupos. Alternativas que ofereçam atenção dirigida a populações com tendência a isolamento e exclusão social devem ser incentivadas por parte de profissionais da saúde e seus dirigentes.

Descritores: HIV; Simbolismo; Pesquisa Qualitativa.

\footnotetext{
1 Artigo extraído da dissertação de mestrado "Significados da atividade grupal no atendimento ambulatorial para portadores de HIVIAIDS" apresentada à Faculdade de Enfermagem, Universidade Estadual de Campinas, Campinas, SP, Brasil.

2 Doutoranda, Universidade Estadual de Campinas, Campinas, SP, Brasil.

${ }^{3} \mathrm{PhD}$, Professor Doutor, Universidade Estadual de Campinas, Campinas, SP, Brasil.
} 


\title{
Symbolic aspects involved in group activity for persons who live with HIV
}

This is a qualitative and descriptive work, which has used the clinical and qualitative method. The sample was composed of nine patients living with HIV. We used the interview technique with semi-structured questions to collect data. The data were analyzed using the method of content analysis. Our objective was to describe the symbolic representations that emerged during the group activity, assigned to patients with HIVIAIDS. We conclude that the symbolic is very strong and representative in the life of this population. The myth surrounding HIV can be overcome by knowledge acquired during meetings in groups. Alternatives that offer care aimed at populations that tend to social isolation and exclusion should be encouraged by health professionals and their managers.

Descriptors: HIV; Symbolism; Qualitative Research.

\section{Aspectos simbólicos envueltos en actividad grupal para personas que conviven con $\mathrm{VIH}$}

\begin{abstract}
Se trata de un trabajo cualitativo y descriptivo, que se utilizó del método clínico y cualitativo. La muestra fue compuesta por nueve pacientes que viven con VIH. Utilizamos la técnica de entrevista con preguntas semiestruturadas, para colectar los datos. Éstos fueron analizados por el método del análisis de contenido. Nuestro objetivo fue describir las representaciones simbólicas emergentes durante la actividad en grupo, atribuidas a pacientes portadores de VIH/AIDS. Concluimos que lo simbólico es muy fuerte y representativo en la vida de esta población. El mito que envuelve el VIH puede ser rompido por el conocimiento adquirido durante encuentros en grupos. Alternativas que ofrezcan atención dirigida a poblaciones con inclinación a aislamiento y exclusión social deben ser incentivadas por parte de profesionales de la salud y sus dirigentes.
\end{abstract}

Descriptores: VIH; Simbolismo; Investigación Cualitativa.

\section{Introdução}

O surgimento do Vírus da Imunodeficiência Humana (HIV) em uma sociedade calcada em estereótipos culturais suscitou em seu âmago uma série de questionamentos morais e a reorganização das condutas sexuais.

A Síndrome da Imunodeficiência Adquirida (Aids) tornou-se uma doença que levava à deformação física e associava-se a grupos considerados discriminados e marginalizados, como os homossexuais, usuários de drogas injetáveis e profissionais do sexo. Essa forma de representá-la mobilizou sentimentos e preconceitos arraigados, evocando comportamentos e políticas discriminatórias ${ }^{(1-2)}$.

O portador de HIV vivência um conjunto de anseios e sentimentos como medo, morte e culpa, além de todo o contexto discriminatório que carrega consigo pelo convívio com a sociedade, o que reforça os hábitos e as expectativas que estão profundamente 
enraizados numa coletividade preconceituosa. O indivíduo portador fica fragilizado, permeado de sofrimento, pois experimenta situações de ameaça à sua integralidade física, emocional e social. Tal situação exige respostas e a necessidade premente de criação de recursos econômicos, políticos, sociais e psicológicos que deem conta de uma problemática com tal magnitude ${ }^{(3-5)}$.

Os reflexos do HIV no mundo incitaram novas formas de lidar com uma doença repleta de símbolos, significados, imagens imprecisas e capciosas, que estimulam atitudes descomedidas de pânico, negação e intolerância às pessoas atingidas por elas. Ao serem implantadas algumas ações de desmistificação da doença, surgem respostas, mitos são esclarecidos e novas tecnologias são desenvolvidas e empregadas no tratamento da doença.

Embora estejamos no início da quarta década de epidemia da Aids, a descoberta do diagnóstico positivo para o HIV continua provocando reações semelhantes àquelas do início da epidemia, onde seus portadores exprimem sentimentos de tristeza, medo e sensação de finitude. Surge o receio de revelar esta nova condição à família e à rede de relações que possui, devido aos julgamentos aos quais poderá ser submetido. Estes passam a viver com a sentença de morte determinada, fomentando questionamentos pessoais sobre sua existência e planos familiares ${ }^{(6)}$. Tais questões fazem com que estas pessoas se isolem socialmente, tornando seu caminho solitário, silencioso e sem acesso a informações que possibilitem melhor entendimento da doença, além de mecanismos que ofereçam preparo frente a esta problemática(7).

A pessoa que vive com HIV e convive diretamente com esse estigma, assume considerações simbólicas para si, passando a ser este um dos grandes obstáculos que a impedem de revelar sua condição sorológica. O medo do abandono, do julgamento e de reações hostis ou negativas por parte de outras pessoas, faz com que o portador não se sinta livre para acessar os serviços de saúde e, por conseguinte, melhorar sua qualidade de vida( ${ }^{(3)}$.

A contaminação e o conviver com a soro positividade são vistos como ameaça à integridade física do ser humano, causando operações mentais, códigos, signos, símbolos abstratos e a formação de conceitos individualizados. Esta atividade resulta em uma resposta afetiva expressa pelo medo do desconhecido, um gerador de valores individuais e crenças da população, evidenciando os significados simbólicos da doença. Este simbolismo é comprovado em vários estudos dirigidos à população soropositiva ${ }^{(1,7-8)}$.

Mesmo antes da linguagem verbal, o homem neste momento dispunha de meios simbólicos de construção, interação e interpretação da realidade. A própria alteridade sempre foi, aos olhos do ser humano, a primeira representação, imagem e signo tomada como extensão de si, o sujeito está em si e está no outro, interagindo e construindo a realidade ${ }^{(8)}$.

Sendo o modelo social baseado nas interações contínuas que se estabelece no dia a dia, dentre as quais os papéis são definidos entre os indivíduos e as relações simbólicas se sustentam em um processo aberto para reafirmações ou mudanças de acordo com a interpretação individual de cada ser, ou seja, o simbolismo somente é constituído através da relação direta de duas ou mais pessoas, fundamentando suas ações naquilo que o coletivo constitui(9).

O simbolismo e as interações contínuas dos seres, também são observados em algumas atividades realizadas por profissionais da saúde. Um exemplo claro destes são atividades em grupo como ferramenta terapêutica. Grupo é um conjunto restrito de pessoas, ligadas por constantes de tempo e espaço e articuladas por sua mútua representação de uma tarefa, a qual constitui sua finalidade, interatuando para isso através de complexos mecanismos de adjunção e assunção de papéis, sendo possível a existência do homem devido às suas relações grupais $^{(9-10)}$.

Intervenções voltadas apenas à recuperação do corpo biológico não respondem de forma plena às necessidades de saúde de pessoas vivendo com HIV na sociedade moderna, pois esta demanda vai além da divisão do ser humano em suas diversas dimensões, a qualidade de vida e a promoção da saúde, induzindo cada vez mais os profissionais a buscarem novas alternativas de assistência que levem em consideração sua integralidade.

O desenvolvimento de grupos na prática de enfermagem não constitui propriamente uma novidade. Vários profissionais desenvolvem seu trabalho em grupo, tanto na assistência, como em atividades junto às equipes multiprofissionais, sendo esta prática muito utilizada na Saúde Pública e no âmbito hospitalar e ambulatorial(10-11).

Observando a complexidade envolvida junto ao portador de HIV/Aids como membro social, trabalhos que ofereçam novas alternativas, estabeleçam novos pensamentos relacionados aos avanços cientíicos, possibilitem conhecer as representações do HIV em seu cotidiano, contribuam para a melhoria da qualidade 
de vida destes através de ações de saúde adequadas e satisfatórias, são justificáveis. Neste sentido, adotamos o objetivo de descrever as representações simbólicas emergentes durante a atividade em grupo, atribuídas por pacientes portadores de HIVIAids em seus encontros mensais.

\section{Método}

Trata-se de um trabalho qualitativo e descritivo, que foi realizado através do método clínico e qualitativo, tendo como local de coleta de dados o ambulatório de DST/Aids que funciona junto ao serviço social de um Hospital Público Universitário situado em uma cidade do interior paulista. O grupo estudado foi constituído há 10 anos e mantêm ocorrência mensal. Composto por pacientes portadores de HIV, em sua maioridade homens. Por ser um grupo operativo misto e aberto o convite e adesão dos pacientes é livre.

Os participantes foram escolhidos de forma intencional ou proposital, ou seja, a escolha foi deliberada por aqueles que apresentaram capacidade de fornecer dados ricos e sustentáveis frente aos objetivos de pesquisa de acordo com sua experiência de vida ou de doença,

Foram inclusos pacientes que vivem com HIV e usam antirretrovirais (ARV), de ambos os sexos, com maioridade atingida, frequentadores do grupo no ambulatório de DST/Aids, com assiduidade mínima de cinco encontros, excluindo do estudo pacientes não assíduos, o que totalizou 9 participantes. Nesse grupo houve predomínio de pessoas do sexo feminino, na faixa etária entre 30 e 51 anos de idade e homens de 49 a 62 anos de idade, com grau de escolaridade de nível fundamental, seguido de indivíduos que possuem ensino médio completo. Grande parte dos estudados não têm profissão ou ocupação, cuidam apenas dos afazeres domésticos. Quanto ao tempo de diagnóstico e não propriamente o tempo de contaminação com o vírus, este varia de 3 a 18 anos. O tempo de permanência no grupo como membro, obedecendo nosso critério de inclusão, ocorre desde 5 participações até 7 anos de permanência.

Utilizamos a técnica de entrevista com perguntas semiestruturadas para coletar os dados. Este tipo de entrevista permite realizar perguntas abertas, porém com foco específico em determinado tema, possibilitando que o entrevistado possa trazer dados importantes sobre o assunto pretendido e evite tangenciar as respostas de forma evasiva. As perguntas abordavam temas como a representação de ser soropositivo na sua vida e a experiência em participar de grupos voltados para sua condição. Os dados foram analisados segundo o método de análise de conteúdo(12), seguindo os seguintes passos: leituras flutuantes de todo o material coletado, seleção das unidades temáticas, codificação dos relatos e constituição das categorias temáticas.

Sendo este trabalho um recorte de uma dissertação de mestrado que envolve pesquisa com seres humanos, a mesma foi aprovada pelo Comitê de Ética e Pesquisa da Faculdade de Ciências Médicas da Unicamp sob o $n^{\circ}$ 0069.0146.000-09. Todos os participantes assinaram o Termo de Consentimento Livre e Esclarecido (TCLE) após serem informados sobre o teor e objetivo da pesquisa.

\section{Resultados e Discussão}

Para apresentar o resultado e discutir sobre a análise dos dados, foram apreendidas nas falas dos sujeitos, as vivências e emoções dos portadores e suas convivências com os membros participantes do estudo no contexto grupal. Após a realização das leituras flutuantes de todo o material coletado, seleção das unidades temáticas e codificação dos relatos, constituímos as seguintes categorias temáticas:

\section{Aprender, conhecer, saber.}

[...] Me instruiu, me ajudando abrir a mente[...] (E6-P7). [...]Eu trago muita coisa vou aprendendo com eles... tirando lições para sua vida[...](E1-P4). [...] As pessoas não têm a mente aberta... (E6-P6).

$\mathrm{O}$ conhecimento que as pessoas trazem consigo sobre a doença, levando-se em consideração seus aspectos epidemiológico, virológico ou infeccioso, mostrou uma dimensão de obscuridade que poderia ser iluminada por um fenômeno que foi nomeado como "abrir a mente", ou seja, algo que não era compreendido, que não era parte de um todo e passa a ser uma constante em si. O conhecimento adentra de forma consciente e internalizada nos pensamentos, e se agrega a partes de um todo, aquele que ali não estava agora se insere e tornase aceitável devido à compreensão fatídica que o envolve. Sendo o conhecimento um conjunto de todas as informações que descrevem o mundo, este prediz e explica a realidade, tornando-a esmiuçada e de fácil metabolização.

O grupo ajuda a gente a abrir a mente, a explicar, a contar para outras pessoas[...] (E6-P7).

Abrir a mente e conhecer mais sobre sua doença denotam certa conformidade causada por esta aproximação com a realidade descrita pela ciência, 
conhecendo seus verdadeiros limites e descartando os mitos criados através do contato discriminatório imposto por si e pelo social. O portador se reconhece modificado pelo conhecimento, por um crescimento em seu "ser", reproduzindo este conhecimento em atitudes de seu cotidiano(13).

A função do grupo, considerando-se componente que propicia o ato de "abrir a mente", está ligada às informações prestadas por profissionais da saúde e experiências vividas pelos próprios membros do grupo, sendo este um espaço que proporciona a troca destas, que somente são aceitas e aderidas pelos participantes devido aos laços fraternais criados entre eles.

\section{O simbolismo do sangue}

[...] ]o que tem no sangue dele tem no meu. (E5-P4). O sangue que corre nas veias de todos nós pode parecer comum, mas trata-se de um líquido essencial, extremamente precioso para nossa vida e sua manutenção. Simbolicamente, o sangue possui um vínculo bastante estreito com o afeto e a relação de irmandade, neste momento usado em rituais de ligações. Símbolo da parte emocional da alma humana, representa também pactos entre os indivíduos, sendo as representações do sangue inúmeras em esferas psicologias, sociais e fisiológicas $^{(14)}$.

Podemos afirmar que os vínculos consanguíneos se estendem de pai para filho e entre irmãos, ou seja, o vínculo natural ou consanguíneo entre pessoas descendentes de um mesmo tronco ancestral, ligadas pelo mesmo sangue ${ }^{(14)}$.

Neste caso, as ligações consanguíneas são ultrapassadas, as semelhanças atribuídas pelo sangue reforçam os vínculos de confiança e igualdade. Onde as diferenças pessoais são inexistentes, o portador se sente protegido, pertencente a um lugar, longe de sua diferenciação em ser portador, uma busca de autoafirmação como condição de igualdade primordial no sentido da condição humana inerente de vida, saúde e dinamismo. Ele se reflete no outro, dentro de seu complexo de igualdade, onde seu mais íntimo torna-se assim visível ao outro, a identificação destes símbolos o torna consciente dos significados produzidos, ocorrendo trocas entre os indivíduos ${ }^{(15)}$. Estas situações somente são possíveis por estes estarem aderidos, fazerem parte deste grupo de iguais, onde os problemas são similares e as soluções são de ordem prática entre todos.

[...]quando eu tenho um problema o grupo todo tem, a gente tenta solucionar tudo junto[...](E5-P5). Estas trocas são evidentes durante o discurso, e a experiência de vida de cada um é assimilada, absorvida, tomada e incorporada pelo outro, que assume responsabilidade parcial pela resolução da problemática em um complexo de igualdade de difícil aferição, onde tudo é simplificado ou possível por esta equidade.

\section{A necessidade do diálogo}

[...]o grupo é fechado, ninguém vai sair ai falando para os outros lá fora o que eu tenho ou o que eu deixo de ter[...](E5-P4). [...] aqui sim eu posso me abrir[...](E7-P4).

Os portadores se reportam a sua condição sorológica como um segredo inviolado, que os tornam prisioneiros de um mundo interior, cercado, fechado pelos muros do preconceito que podem recair sobre si, onde a convivência grupal de certa forma torna-se uma proteção.

Esta "fortaleza" que é constituída em sua volta os tornam vulneráveis e abertos a estigmatização atribuída pela sociedade. Nas falas seguintes podemos observar que o fator representativo do estigma se deve a sociedade de forma generalizada, e não a pequenos grupos sociais, como as pessoas próximas, familiares e amigos.

[...] ]eu não comento com ninguém, eu faço o possível para não descobrirem...porque eu acho que existe muito preconceito ainda[...] (E7-P4). [...]aqui eu converso o que eu não converso na rua[...] (E4-P5). Apenas algumas pessoas são merecedoras, escolhidas para partilhar este segredo, sendo este alguém que de certa forma é comum em seu modo de vida ou colocação social e nem sempre são pessoas ligadas a vínculos familiares ou de amizade. Estes são definidos ${ }^{(16)}$ como um conjunto de indivíduos do qual o estigmatizado pode esperar apoio, são pessoas que compartilham seu estigma e em virtude disto são conhecidos e definidos como "seus iguais".

Estas pessoas ditas como "iguais" são vistas como normais, mas cuja situação especial o levou a participar de forma íntima e secreta como portador, que fez com que o estigmatizado simpatizasse com ela, ocasionando certa aceitação.

Outra forma de definir pessoas menos intimamente ligadas, mas que partilham deste segredo são os "informados". São aqueles que conhecem o seu segredo, e diante destas pessoas não é preciso se envergonhar nem se autocontrolar, pois sabe que será considerado como uma pessoa comum. Um tipo de pessoa "informada" é aquela cuja informação vem de seu trabalho e das ações empreendidas pela sociedade em relação a eles, como enfermeiras, terapeutas e assistentes sociais. Assim, a empatia 
com os profissionais de saúde é tão marcante e evidente, que o portador cria fortes vínculos com estes profissionais, vínculos tão densos que podem ultrapassar os muros institucionais ${ }^{(16)}$.

[...]Converso com meu marido, mas é difícil às vezes conversar, por que ele não tem, então é difícil (E4-P5). [...]Aqui eu comecei a conversar porque eu ficava calada, eu não falava pra ninguém, eu guardei um ano pra mim, um ano! Só pra mim, sabe? (E4-P4). [...] Meu problema ninguém sabe (E7-P4). O portador demonstra medo real em ser "descoberto", em seu segredo ser revelado, alguns passam parte de sua vida evitando tocar no assunto, mesmo quando sua condição sorologia é conhecida pelos que o cercam.

O portador se resguarda, muitas vezes de sua própria consciência, em aceitar-se, em se ver como soropositivo, passando muito tempo evitando a afirmação de sua condição pela audição de sua voz ao fazer tal afirmação, passando a não ser real aquilo que somente ele sabe, como uma ilusão que não necessita de afirmações, sendo isto o gerador de grande angústia.

Os entrevistados demonstraram grande necessidade de expressar suas angústias em serem portadores, em guardar este segredo, até de seu próprio consciente. Ao falar sobre sua condição sorológica, alcançaram um nível terapêutico caracterizado na fala com a referência de bem-estar, de se sentir melhor.

De forma unânime, os participantes da pesquisa dizem ser no grupo, o local eleito para falar de qualquer assunto relativo ao HIV ou não. Assim como na literatura, eles atribuem esta atitude a certeza de estarem em local protegido pela igualdade de sua classe ${ }^{(16-17)}$.

[...] No grupo é liberado o grupo tem o que eu tenho [...] aqui sim eu posso me abrir[...] (E7-P4). [...] Aqui eu sei que todas tem [...] me sinto segura[...] (E5-P4). Esta referida segurança em poder falar, dialogar, contar sem medo, sem limites impostos pela sociedade, por meio de conceitos éticos e morais e a qualidade de estar em um meio, onde todos são pertencentes a uma mesma classe de estigmatizados, conforta os membros que dele participam.

O vínculo criado pelo diagnóstico reforça noções de habitat natural. A afirmativa de confiança nos membros do grupo e a segurança de pertencente a ele é muito forte, pontual e marcante. A noção de segurança pode ser comparada a conceitos relacionados como confiança, pois ambos estão relacionados à percepção de proteção, ao estar protegido de riscos, perigos e perdas ${ }^{(17)}$.

[...]Aqui eu me acho aberta para conversar como se eu fosse uma psicóloga, como se fosse uma assistente social, um ginecologista com quem a gente pode falar[...] (E5-P4). Sobre a ótica do portador, este pertence a um lugar sem inibições, sem medo de errar e ao mesmo tempo afirmando a segurança que sente e que outros membros do grupo atribuem a ele.

Sua percepção pessoal se modifica e passa a adquirir uma posição equiparada a um profissional, devido à visibilidade deste perante o grupo e a confiança em seus conhecimentos, o que demonstra novamente uma percepção grupal sem grau de hierarquia frente ao profissional de saúde dentro do grupo ${ }^{(11)}$.

O apoio do grupo é fundamental para a aceitação de si mesmo como portador e, ao mesmo tempo, participante de um grupo social. Os sujeitos se apropriavam dos relatos pessoais de outros membros do grupo sobre suas experiências de vida, reproduzindo a experiência alheia em seu cotidiano e reformulando-a como parte do seu aprendizado em lidar com situações relacionadas à doença e tudo que diz respeito a ela. Em outras palavras, assimilam essas experiências e as utilizam repetidas vezes como meio de reproduzir o conhecimento. É como lidar com algo novo, ainda desconhecido, que toda a sua experiência de vida não foi suficiente para responder.

Algumas mudanças observadas durante a fala não podem ser explicadas apenas pela formulação do pensamento consciente. Trata-se de uma mudança de todo o comportamento e colocação corporal, abrangendo a percepção do ser em si, construída por várias reformulações internas, levando ao rompimento do "eu":

Eu me sentia uma menina, gostava de tudo, tinha vaidade, usava roupa curta, pensava em viver, viajar, trabalhar muito, depois que eu descobri eu morri, eu estou assim, um isopor, então é horrivel sentir essa sensação que você não é mais aquela pessoa [...] (E2P1). Essa separação entre seres distintos é eloquente. De um lado, uma pessoa saudável, nascida em um berço familiar, liberta de males, longe dos males carnais e mundanos, porém soronegativa. De outro, um ser soropositivo, merecedor dos castigos divinos e malignidades devido à sua condição de soropositivo.

\section{Adesão terapêutica}

O conceito de "adesão à terapêutica" está voltado principalmente à adesão ao tratamento de algumas enfermidades específicas. Compreende a utilização de, no mínimo, $80 \%$ dos medicamentos prescritos ou de outros procedimentos, observando-se horários, doses e duração do tratamento ${ }^{(18)}$. 
Uma definição mais ampla e abrangente assinala que a adesão é um processo dinâmico e multifatorial, o qual inclui aspectos físicos, psicológicos, sociais, culturais e comportamentais, e requer decisões compartilhadas e corresponsabilizadas. Trata-se de uma negociação entre o usuário e os profissionais de saúde, em que são reconhecidas as responsabilidades específicas de cada uma das partes. Mais do que a simples ingestão de medicamentos, a adesão terapêutica inclui o restabelecimento do paciente, o acesso à informação, o acompanhamento clínicolaboratorial e a adequação aos hábitos e necessidades individuais e compartilhadas ${ }^{(6,18)}$.

Esses conceitos permitem concluir que a adesão terapêutica é mais um processo introspectivo do que uma ação de saúde. A participação em um grupo faz parte de processo de adesão terapêutica, mas torna-se um veículo que conduz o portador de forma diretamente proporcional à adesão.

A adesão ao tratamento está diretamente ligada à aceitação da positividade, ao aderir ao tratamento, o portador está afirmando, mesmo que inconscientemente, sua condição sorológica. Aceitar o fato de ser portador de uma doença crônica significa reconhecer a condição de doente. Eu não me via assim, eu me via portadora, mas não me via tomando o remédio, não admitia tomar o remédio. Hoje eu tomo o remédio e aceito por causa do grupo (E5-P4). Aprendi como tomar os remédios, como conviver com o esposo, como não perder as consultas, não perder o horário dos remédios, tudo ficou mais fácil [...] (E3-P4).

A convivência com o grupo faz com que o processo de aceitação do tratamento medicamentoso comece a se firmar entre os sujeitos estudados. Torna-se perceptível para o próprio indivíduo que este processo de transformação é obtido pela troca de informações e pelas vivências de outros participantes que neste momento estabeleceram sua adesão. Estas experiências são, reconhecidamente, o principal fator para levar a uma mudança de comportamento frente à utilização do medicamento.

A troca de informações entre os participantes do grupo, tanto de suas experiências pessoais como aquelas prestadas pelos profissionais envolvidos na dinâmica de grupo, denota um estágio diferenciado do anterior. No início, o uso de antirretrovirais os remetia à doença, agora passaram a ser o caminho para a manutenção da vida e parte inseparável do seu cotidiano.

\section{Convívio social e familiar}

Eu comecei a me soltar mais, a brincar mais [...] com meus filhos, com meu marido, daí comecei a me soltar[...] (E4-P4). Agora é normal, tenho um relacionamento normal com meu esposo como qualquer outra pessoa, como uma pessoa normal (E4-P1).

O convívio familiar tem grande importância na vida das pessoas. São os vínculos familiares que estabelecem o primeiro espaço de convivência do ser humano e servem como referência fundamental para a incorporação de valores éticos. Neste núcleo nascem, crescem e se adquirem os valores morais. É no convívio familiar que as pessoas vivenciam situações de afetividade e constroem suas representações, juízos e expectativas.

A convivência entre os cônjuges adquire um sentido especial em alguns casos, à medida que o casamento serve como instrumento de construção, com a função social de criar uma determinada ordem, capaz de dar novo sentido à vida(19).

O diagnóstico de HIV altera o conceito de como se colocar diante do próximo, levando o portador a procurar se adaptar à sua nova condição ou a buscar se recolocar junto à família e ao parceiro. Tal consideração pode estar ligada à culpa que assume para si, por ter contraído o vírus. As relações familiares são abaladas e reestruturadas em um processo contínuo até a sua aceitação, revelando no decorrer deste processo novos significados ${ }^{(3,20)}$.

No caso do portador de HIV, as relações podem ser rompidas por medo da contaminação, principalmente no caso de soro e discordantes. No início, pode ocorrer um distanciamento entre os cônjuges, seguido por um período de maior proximidade, ligado à cumplicidade em partilharem de um "mundo secreto", estreitando os vínculos conjugais com o fortalecimento dos laços matrimoniais.

Mudou tudo! Mudou tudo, me ensinou como conviver com a sociedade e a voltar para a sociedade[...] você vê como as outras pessoas reagem sobre a sociedade[...] (E5-P7).

$O$ isolamento social surge nas falas como consequência do rompimento de vínculos. A doença leva a pessoa a se afastar da família e do convívio social, evitando assim o julgamento e a condenação moral, considerando-se que esta é uma doença estigmatizante, que cristaliza no imaginário social simbolizações acerca da transmissão do $\operatorname{HIV}^{(3,20)}$.

A sensação de inércia que surge logo após o diagnóstico vai desaparecendo com o decorrer do tempo por meio da participação no grupo. As angústias e incertezas existenciais iniciam um processo de amadurecimento, atenuando todo o seu potencial estigmatizante. A pessoa passa a se sentir livre; suas estruturas e mecanismos internos estão preparados para enfrentar todo o contingente discriminatório ligado ao HIV ao tentar se recolocar socialmente. As trocas de experiências que ocorrem no ambiente 
grupal fortalecem e fundamentam esta condição. Além de permitir o retorno às atividades normais e ao convívio familiar sem as resignações, estabelecendo novos rumos e arranjos para sua recolocação social.

Como os portadores que participam do grupo se encontram em fase de aceitação individualizada, as experiências referentes a enfrentamentos sociais são diferenciadas, favorecendo a troca de experiências enriquecedoras, que posteriormente irão propiciar a reprodução destes enfrentamentos nas mais diversas situações.

\section{Considerações Finais}

Consideramos que as questões simbólicas permeiam de forma representativa a vida desta população. Parte de suas crenças é baseada em vivências de uma realidade passada e remota, na qual o conhecimento sobre a doença ainda era insipiente e fragmentado.

O simbolismo encontrado nas vivências grupais é fundamentado pela representação coletiva de uma realidade diária e constante nesta população. O convívio permanente com o estigma e a discriminação advinda da sociedade é que torna presente estas formas de representação. As representações não simbólicas são trabalhadas e resolvidas pelo processo de interação em grupo, oferecendo alívio às angústias provenientes do silêncio e da solidão causada pelo contingente discriminatório experimentado.

O significado de ser portador de HIV se mantém idealizado. Apesar do avanço médico ocorrido nas últimas décadas, a doença ainda é considerada fulminante. $O$ diferencial desta população é marcado pelas ressignificações; os mitos que cercam o HIV podem ser rompidos e esclarecidos ao portador através do conhecimento adquirido durante os encontros grupais sobre a doença. Ocorrendo um processo de aceitação da doença, da condição sorológica e dos enfrentamentos pessoais, tornamse responsáveis por seu tratamento e sua saúde, aderindo de forma plena ao tratamento proposto pela equipe de saúde.

As equipes de saúde podem oferecer alternativas que proporcionem atenção dirigida às populações com tendência a isolamento e exclusão social, sendo sempre incentivadas por parte de profissionais da saúde e seus dirigentes, pois as atividades grupais possuem baixo custo e grandes benefícios.

\section{Referências}

1. Villela WV, Monteiro SG. Estigma e saúde: reflexões a partir da prostituição, do aborto e do HIV/Aids entre mulheres. Epidemiol Serv Saúde. 2015;24(3):531-40.

2. BosAER, Pryor JB, Reeder GD, Stutterheim SE. Stigma: Advances in theory and research. Basic Appl Soc Psychol. 35(1): 1-9. doi.org/10. 1080/01973533.2012.746147

3. Medeiros APDS, Araujo VS, Moraes MN, Almeida AS, Almeida JN, Dias MD. A experiência da soropositividade para grávidas com HIVIAIDS: preconceito, dor, trauma e sofrimento pela descoberta. Rev Enferm UERJ. 2015;23(3):362-7.

4. Zucchi EM, Paiva VSF, França IJ. Intervenções para reduzir o estigma da Aids no Brasil: uma revisão crítica. Temas Psicol. 2013;21(3):1067-87.

5. Maliska ICA, Padilha MI, Vieira M, Bastiani J. Percepções e significados do diagnóstico e convívio com o HIV/aids. Rev Gaúcha Enferm. 2009;30(1):85-91.

6. Dantas MS, Abrão FMS, Costa SFG, Oliveira DC. HIV/ AIDS: significados atribuídos por homens trabalhadores da saúde. Esc Anna Nery. 2015;19(2):323-30.

7. Porto TSAR, Silva CM, Vargens OMC. Cuidando de mulheres com HIVIAIDS: uma análise interacionista na perspectiva de mulheres profissionais de saúde. Rev Gaúcha Enferm. [Internet]. 2014 [Acesso 9 dez 20159]; 35(2):40-6. Disponível em: http://seer.ufrgs.br/index.php/ RevistaGauchadeEnfermagem/article/view/41253

8. Castanho P. Uma introdução aos grupos operativos: teoria e técnica. Vínculo - Rev NESME. 2012;9(1):1-60.

9. Nhamo-Murire M, Campbell C, Gregson S. Community group membership and stigmatising attitudes towards people living with HIV in eastern Zimbabwe. J Commun Health. 2014;39:72-82.

10. Lucchese R, Vera I, Benicio PR, Silva AF, Munari DB, Fortuna CM. Use Of The

Operative Group In Health Care: An Integrative Review. Cogitare Enferm. 2014;19(4):762-

71.

11. Spadini LS, Souza MCBM. Conceito de grupo na percepção de enfermeiros na área de saúde mental e psiquiatria. SMAD, Rev Eletrôn Saúde Mental Álcool Drog. (Ed. port.) set.-dez. 2011 [Acesso 10 jan 2016];7(3):133-8. Disponível em: http://pepsic.bvsalud. org/pdf/smad/v7n3/04.pdf

12. Minayo MCS, organizador. O desafio do conhecimento: pesquisa qualitativa em saúde. $9^{a}$ ed. São Paulo: Hucitec; 2006.

13. Heller A. O cotidiano e a história. $10^{\mathrm{a}}$ ed. São Paulo: Paz e Terra; 2014. 
14. Borlot AMM, Trindade ZA. As tecnologias de reprodução assistida e as representações sociais de filho biológico. Estudos Psicol. 2004;9(1):63-70.

15. Carvalho VD, Borges LO, Rêgo DP. Interacionismo simbólico: origens, pressupostos e contribuições aos estudos em Psicologia Social. Psicol Cienc Prof. 2010;30(1):146-61.

16. Goffman E. Estigma: notas sobre a manipulação da identidade deteriorada. Rio de Janeiro: LTC; 2008.

17. Pichon-Rivière E. O processo grupal. $8^{\mathrm{a}}$ ed. São Paulo: Martins Fontes; 2009.

18. Leite SN, Vasconcellos MPC. Adesão a terapêutica medicamentosa: elementos para a discussão de conceitos e pressupostos adotados na literatura. Ciênc Saúde Coletiva. 2003;8(3):775-82.

19. Franch M, Neves EM. Roturas e Suturas: Anotações sobre a experiência do tempo entre pessoas vivendo com HIV/aids [Internet]. In: Araújo E, Duque E, Franch M, Durán J. Tempos Sociais e o Mundo Contemporâneo - As crises, As Fases e as Ruturas. Minho (PT): Universidade do Minho; 2014. p. 68-78. ISBN 978-989-8600-23-3. Acesso em: 11 fev 2016. Disponível em: http://www. lasics.uminho.pt/ojs/index.php/cecs_ebooks/article/ view/2057/1979

20. Lima F, Pichelli A, Silva J. A convivência com HIV/ AIDS em mulheres soropositivas - A convivência com HIVIAIDS em mulheres. CIAIQ 2014. 2015;2:388-93. 